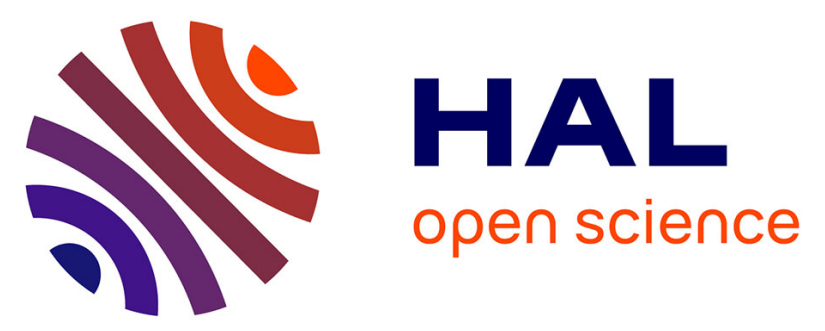

\title{
The Use of Solar Energy for the Production of Fullerenes and Porous Silicon
}

\author{
D. Laplaze, P. Bernier, C. Journet, J. Sauvajol, D. Bormann, G. Flamant, M.
}

Lebrun

\section{- To cite this version:}

D. Laplaze, P. Bernier, C. Journet, J. Sauvajol, D. Bormann, et al.. The Use of Solar Energy for the Production of Fullerenes and Porous Silicon. Journal de Physique III, 1997, 7 (3), pp.463-472. 10.1051/jp3:1997134 . jpa-00249588

\section{HAL Id: jpa-00249588 https://hal.science/jpa-00249588}

Submitted on 1 Jan 1997

HAL is a multi-disciplinary open access archive for the deposit and dissemination of scientific research documents, whether they are published or not. The documents may come from teaching and research institutions in France or abroad, or from public or private research centers.
L'archive ouverte pluridisciplinaire HAL, est destinée au dépôt et à la diffusion de documents scientifiques de niveau recherche, publiés ou non, émanant des établissements d'enseignement et de recherche français ou étrangers, des laboratoires publics ou privés. 


\title{
The Use of Solar Energy for the Production of Fullerenes and Porous Silicon
}

\author{
D. Laplaze $\left(\left(^{1, *}\right)\right.$, P. Bernier $\left({ }^{1}\right)$. C. Journet $\left({ }^{1}\right)$, J.L. Sauvajol $\left({ }^{1}\right)$, D. Bormann $\left({ }^{1}\right)$, \\ G. Flamant $\left({ }^{2}\right)$ and M. Lebrun $\left({ }^{2}\right)$ \\ (1) Groupe de Dynamique des Phases Condensées, Unıversité de Montpellier II, \\ 34095 Montpellier, France \\ $\left({ }^{2}\right)$ Institut de Science et de Génı des Matériaux et Procédés, BP 5, Odeıllo, \\ 66125 Font-Romeu, France
}

(Received 6 May 1996, revised and accepted 23 December 1996)

PACS.81.05 Tp - Fullerenes and related materials, diamonds, graphite PACS 81.05.Rm - Porous materials, granular materials

\begin{abstract}
We have previously shown that the high intensity of solar radiation, obtained with the Odello (France) solar furnace facllities, can be used to vaporize graphite in inert gas atmosphere and to produce fullerenes. After a short survey of the vaporization-condensation method used here, we discuss some of the mechanisms of formation of these molecules and the possibility of increasing the yield, which currently reaches $20 \%$. This technique which presents substantıal advantages (use of powders, small rate of UV radıatıon, possibility of varying pressure and evaporation rate) allow a better knowledge of the mechanisms of formation of fullerene and can be easily used for other material than carbon As an example. we give first results of production of one porous silicon species exhibiting a strong photoluminescent effect
\end{abstract}

The high intensity of solar radiation, obtained with the Odeillo solar furnace facilities can be used to vaporize different materials under various atmosphere compositions. The obtained material is generally made of aggregates, nanoparticles or clusters. In these vaporizationcondensation experiments, the nucleation of nanophases or clustering of atoms occurs in the vapour phase, close to the vaporized target followed by condensation in the cold part of the reactor. The main advantage of using the solar furnace lies in the fact that the high temperature zone of the sample is confined near the focus so that designing reactors is very simple. We can build them with common material such as pyrex glass even if the temperature of the target reaches $3000 \mathrm{~K}$. The solar furnace approach. described in this paper, may provide a solution to the problems encountered in present methods of production of fullerenes and carbon nanotubes and can lead to a better knowledge of the formation mechanisms. Since their discovery in 1985, the optimization of a large fullerenes production at high yield is still a real problem as their prohibitive cost reduces the development of studies and practical uses for these materials. Various methods have been explored which can be classified in three categories: the first one consists in vaporizing graphite in an inert gas atmosphere [1] and including laser-vaporization, resistive heating, electric arc method, inducting heating and vaporization of carbon in focussed

${ }^{*}$ ) Author for correspondence (e-mail: laplaze@gdpc univ-montp2.fr) 
sunlight; the second uses the combustion of benzene [2] or hydrocarbons [3] in oxygen-deficient flames to produce soot; and the third one is founded on a pure chemical reaction. Currently, the electric arc method is mostly used $[4,5]$ even if the production is limited to several tens of grams per hour. So, it appears necessary to find the way for producing large amounts of fullerenes at low cost, not only for the most abundant $\left(\mathrm{C}_{60}\right.$ to $\left.\mathrm{C}_{84}\right)$, but also for higher fullerenes and other derivative compounds like substituted molecules, metallofullerenes or carbon nanotubes. In 1993 , various research groups $[1,6,7]$ have shown that it is possible to produce fullerenes in rarefied inert gas atmosphere by direct vaporization of graphite in focussed sunlight. Our initial experiments have been performed at small scale, but if the production is still not very great, the yield can reach $20 \%$ [8]. We can prepare samples for laboratory use and explore the effect of varying physical conditions during synthesis. This vaporization-condensation method can also be used for other materials, like silicon, and gives interesting results

\section{Vaporization-Condensation in Rarefied Inert Gas Atmosphere}

We have used a $1.5 \mathrm{~kW}$ (or $2 \mathrm{~kW}$ ) solar furnace of the Odeillo Institute which gives a focussed power close to $1100 \mathrm{~W}(1500 \mathrm{~W})$ for direct solar flux around $850-900 \mathrm{~W} \mathrm{~m}^{-2}$. Our general design has been described previously [8]. The experimental chamber which can be adjusted to the focus is schematically drawn in Figure 1. The stand part R, surrounded by the Pyrex balloon flask, is a water cooled brass cylinder which support the target and the cellulose filter to collect the soot. The target can be a graphite rod or a graphite crucible filled with graphite powder, mixture of graphite and other materıals, or pure silıcon. This chamber was first evacuated to $10^{-2}$ mbar and purged and then swept by Ar gas during sublimation. The pressure could be varied from vacuum to 350 mbar.

\section{Vaporization of Graphite}

With this reactor, evaporation of graphite is possible and gives a small amount of soot which contains fullerenes (Fig. 2), but two major difficulties arise: first the evaporation rate is very small for a standard graphite rod; second we must prevent the deposition of the soot on the balloon flask This last problem can be partly solved using Ar gas which sweeps the soot out of the chamber most efficiently than He. Last improvement consists of the use of a graphite pipe, surrounding the target, which is linked to the filter and vacuum pump so that the carbon vapours are directly drawn down to the filter

The small value of the evaporation rate is due to the high thermal conductivity and high emissivity of graphite. It would be necessary to balance these thermal losses to increase the temperature of the front face of the target in order to increase the evaporation rate and efficiency which is very likely dependent on the temperature of the vaporization zone. According to the works by Smalley and the Rice Unversity group $[1,9,10]$, we can summarize the different steps of formation of fullerenes as follows.

Evaporation must produce atomic carbon vapour (high temperature) which is expanded in a dark region where temperature is high enough (typically $1500 \mathrm{~K}$ ) to anneal most of the condensing vapour into fullerenes. If the local temperature in the vaporization zone is great enough, like near the impact point in laser method or at the top of the tips in an electrical arc, the density of large and undesired clusters of carbon, $\mathrm{C}_{x}$. that form immediately after vaporization is weak. Expansion arises naturally when the carbon vapour is drawn away from the vaporization zone. This is the case for laser vaporization where efficiencies can reach $40 \%$. Unfortunately, with the electrical arc method, the clustering zone is highly irradiated by the UV light produced by the arc and this radiation induces a photodestruction of the fullerenes. 


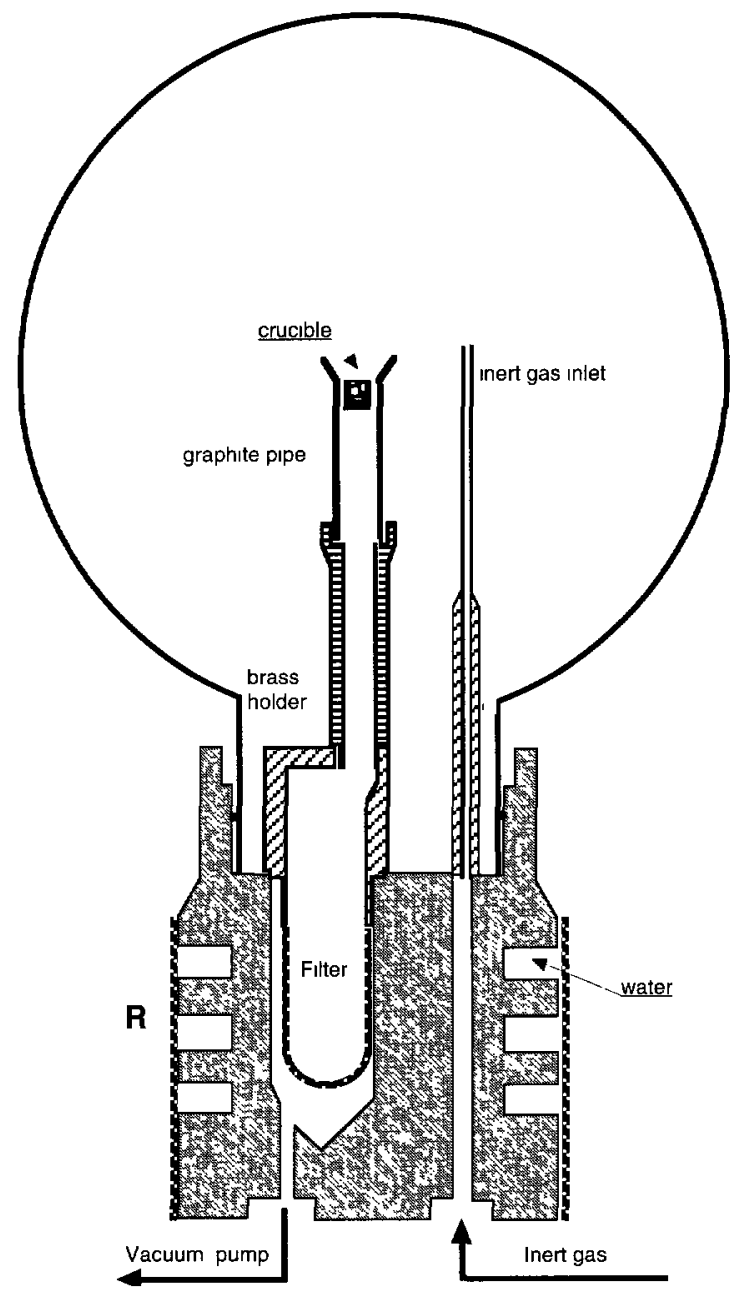

Fig. 1. - Solar generator of fullerenes. The graphite pipe acts as a thermal screen and is linked to the filter to canalize the carbon vapour

With small tips (diameter \# $6 \mathrm{~mm}$ ) electrical arc efficiency can reach $15 \%$ but any attempt to get larger production increasing the rod diameter leads to a strong decrease of efficiency linked with the size of the rods [1]. With the small scale solar experiment, where the temperature in the vaporization zone is smaller $(3000 \mathrm{~K})$, the density of undesired large carbon clusters remains high and affects the efficiency. But one can use a part of the focussed light to bleach out these undesired clușters.

In order to increase the front temperature of the target we have performed a simplified energy balance analysis previously published [8] and found some solutions in changing the shape of the target. Another way to increase the sublimation rate consists in using powdered graphite. Its thermal conductivity is lower and the roughness of the front surface also induces a trapping effect of radiation. The front temperature cannot be measured with pyrometer on account of the reflected and scattered light. It was deduced from the values of evaporation rate in a lot of experiments using either graphite rods or powders [8] 


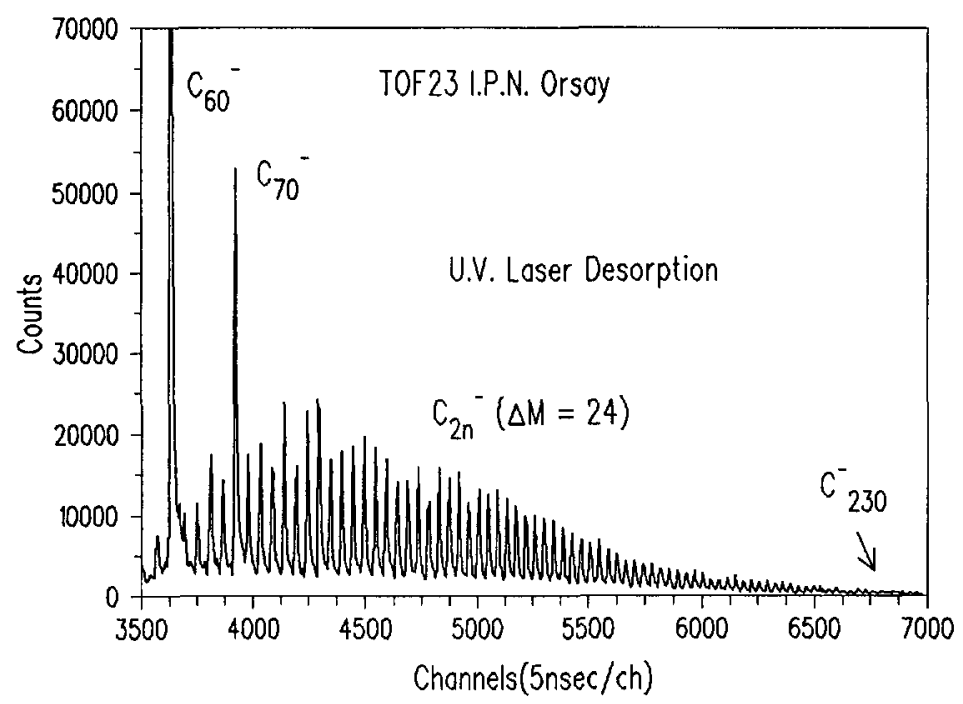

Fig 2. - Mass spectrum of the soot.

The higher temperature we have obtained is close to $3050 \mathrm{~K}$ using powdered graphite set in a graphite crucible, surrounded by a graphite pipe linked to the filter. This pipe, which is used to canalize the carbon vapour, is also heated by the sunlight at its top and acts as a thermal screen. With this last improvement, the evaporation rate is close to $120 \mathrm{mg} \mathrm{h}^{-1}$ with a crucible top surface of about $30 \mathrm{~mm}^{2}$.

\section{Fullerenes: Experimental Results}

One of the advantages of the solar method is the possibility to adjust the evaporation temperature and the sublimation rate by a convenient choice of the inert gas pressure and of the incident light flux, if the thermal losses are conveniently reduced Other advantages are the small UV rate in the sunlight and the possibility of using powders of pure graphite or mixture of graphite and other species With the improved experimental set-up, we have performed some tests to investigate the major factors controlling the fullerene yield or to point out some of the formation mechanisms.

3.1. Pressure Effects. - First observations are related to the pressure effects of the pressure on the toluene soluble part of the soot which contains principally $\mathrm{C}_{60}$ and $\mathrm{C}_{70}$. Concentrations are measured in the UV-visible range $(800-300 \mathrm{~nm})$ where the solutions obey the Lambert-Beer law [11]. Some of the samples have also been checked by mass spectroscopy. Our results are summarized in Table I, for different pressures and for two selected evaporation rates (or temperatures as these two parameters are strongly linked). We do not observe significant variations of the ratio $\mathrm{C}_{70} / \mathrm{C}_{60}$ with pressure at constant evaporation rate. Similar conclusions have been reported by Achiba [12] in the case of laser method or electrical arc even for higher $\mathrm{C}_{2 n}$ molecules. The yield for each kind of molecules remains the same if the pressure is large enough so the inert gas can support the expansion of carbon vapours. Slight changes of yield and composition with the evaporation rate (and vaporization temperature) have been detected, certainly related to the density of carbon atoms in the vaporization zone. 
Table I - Measured values of $\mathrm{C}_{70} / \mathrm{C}_{60}$ ( $2 n$ mole) and efficiencies $Y$ from UV-Vis spectra. Numbers in brackets are the values obtained for the same samples by mass spectroscopy analysis. $Y=$ (Mass of toluene-soluble products)/(total mass of the soot).

\begin{tabular}{|c|c|c|c|c|c|}
\hline Pressure (nb) & 5 & 50 & 70 & 110 & 350 \\
\hline $\mathrm{C}_{70} / \mathrm{C}_{60}$ & & & & & \\
\hline $\begin{array}{l}\text { Evap rate } \\
120 \mathrm{mg} \mathrm{h}^{-1}\end{array}$ & & $34 \%$ & $34 \%$ & $35 \%$ & $\begin{array}{c}35 \% \\
(35 \%)\end{array}$ \\
\hline $\begin{array}{l}\mathrm{C}_{70} / \mathrm{C}_{60} \\
\text { Evap. rate } \\
80 \mathrm{mg} \mathrm{h}^{-1}\end{array}$ & . & $30 \%$ & & $\begin{array}{c}30 \% \\
(31 \%)\end{array}$ & \\
\hline $\begin{array}{l}\text { Efficiency Y } \\
\text { Evap. rate } \\
120 \mathrm{mg} \mathrm{h}^{-1}\end{array}$ & & $12 \%$ & $20 \%$ & $9 \%$ & $7 \%$ \\
\hline
\end{tabular}

The pressure of inert gas is one of the principal factors controlling the yield. At low pressures efficiencies are very weak because there are too many interactions between the carbon atoms and the efficiency therefore increases with the pressure. But for higher pressures, the gas flow rate increases for a given vacuum pump and becomes too high to allow the destruction of undesired cluster in the enlightened region. Finally, we find that the efficiency reaches a maximum close to $20 \%$ for a pressure around $70 \mathrm{mb}$ in our reactor. This value depends on the shape of reactor and focal area and is linked to the flow rate of the inert gas. Final tests, in an initial stage, deal with the measurement of efficiencies at constant pressure for different flow rates of the Ar gas. It seems from our first experiments that this parameter also has a very important effect on the fullerene yield

3.2. Production of ${ }^{13} \mathrm{C}$ Enriched Fullerenes. - Isotopic distribution in each kind of fullerene molecules produced by evaporation of a mixture of powdered natural graphite and ${ }^{13} \mathrm{C}$ shows that the first step of formation is the clustering of isolated carbon atoms. This result is in agreement with the work by Ebesen et al. [13] who have studied the formation of ${ }^{13} \mathrm{C}$ enriched fullerenes produced with electrical arc. They have shown that the isotopic distribution observed in mass spectra can be deduced from vapour composition by a binomial law [14], only in the case where fullerenes grow from small aggregates themselves formed from carbon atoms in the vaporization zone We find, from our experiments, that samples can be described as the result of clusterıng from a vapour mixture which has the same composition as the starting material. This result is true for all tested compositions between natural graphite and $30 \%$ enriched powder. This is one of the advantages of solar generation of fullerenes compared to the arc method used in our laboratory [15], where it is necessary to use homogeneous enriched graphite rods which are more difficult to obtain than an homogeneous mixture of powder.

3.3. Vaporization of Graphite in Presence of Other Species. - Some tests have been performed to investigate the vaporization of graphite powder mixted with other species like pure cobalt, cobalt chloride, silicon or boron. Using mixture with pure cobalt we obtain fullerenes with an efficiency slightly greater than with pure carbon. It is also possible to produce fullerenes using mixture with cobalt chloride, but with reduced efficiency and mass spectra exhibiting, at low mass, the presence of carbon clusters containıng chlorine atoms. Their 

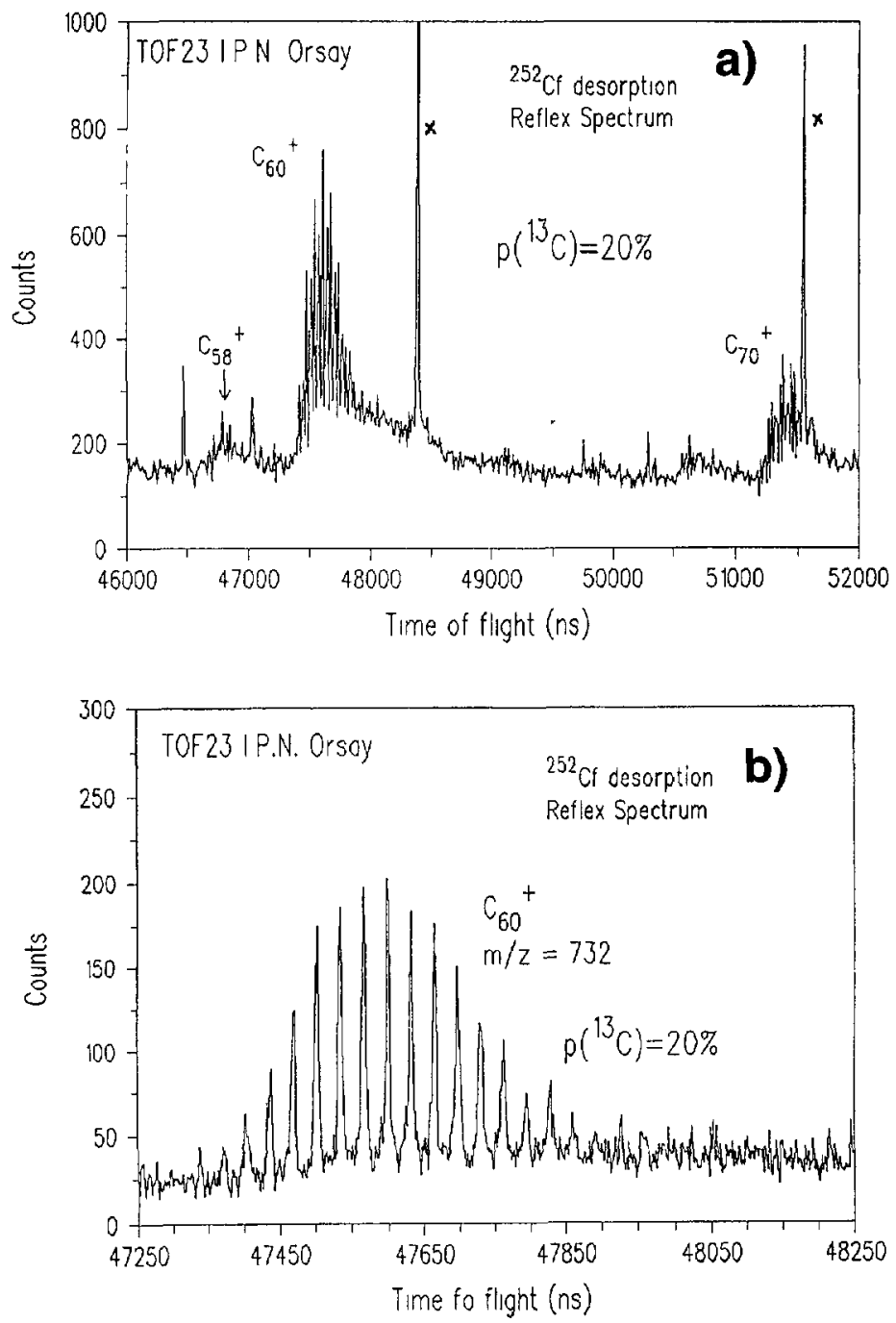

Fig. 3. - Mass spectrum of ${ }^{13} \mathrm{C}$ enriched fullerenes (a) and details of the isotopic distribution of ${ }^{13} \mathrm{C}$ in $\mathrm{C}_{60}$ molecules (b). The starting material is a mixture of $80 \%$ natural graphite powder and $20 \%$ pure ${ }^{13} \mathrm{C}$ powder set in a graphite crucible (the pics labeled $\mathrm{X}$ are due to $\mathrm{Al}_{2} \mathrm{O}_{3}$ clusters originating from sample holder).

structure needs to be solved for comparison with the results reported by Schwarz [16]. This is a way to find the precursors of fullerenes and have a better understanding of the mechanisms of formation. Similarly weak efficiencies have been observed using a mixture of graphite and silicon and it has not been possible to produce fullerenes from a mixture of graphite and boron. Such differences can be explained by the reactivities of the different species in regard with the dangling bonds which appear in the first steps of clustering of the fullerenes. Some of them, like cobalt, can be easily substituted by a carbon atom and can favour the formation of the molecules; they can play an important role during the growth of nanotubes and other studies 
have shown [17] that $\mathrm{Y}, \mathrm{Fe}, \mathrm{Ni}$ can be considered as catalysts for such materials. In the case of boron, the strong chemical bond with carbon leads to boron carbide which directly grows on the sides of the crucible.

3.4. Further Developments. - According to these experiments, possible improvements of the method lies in the increase of the target temperature and the use of a part of the focussed power to bleach out the carbon vapour near the target. They are not easy to perform with small solar furnaces as their focus areas are small (diameter $=1.5 \mathrm{~cm}$ ) and as their radial flux distribution varies very sharply. However, the great $1 \mathrm{MW}$ solar furnace may provide a solution to this inherent problem. In this case the useful part of the focus is 20 times larger and the variation of the radial distribution is smoother. Even with such a reduced density of flux, the useful power can provide temperatures higher than $3300 \mathrm{~K}$ on larger targets. Next tests will be performed in this larger furnace and a new design is currently in preparation for these experiments.

\section{Nanoporous Silicon}

Using the same experimental set-up in the focus of a $2 \mathrm{~kW}$ solar furnace, it is very easy to sublimate powdered crystalline silicon set in a graphite crucible, in argon atmosphere, under a pressure around $100 \mathrm{mb}$. The result is a surprising yellow-orange material condensed in the cellulose filter. This material exhibit optical properties very similar to those of the thin films obtained by Melinon [18] using low energy cluster beam deposition. The Raman spectra reported in Figure 4a do not exhibit the sharp line of crystallıne silicon (Fig. 4b) but a weak peak shifted towards lower frequencies. Refined observation (Fig. 4c) shows the presence of a very weak line at $2.345 \mathrm{eV}$ likely originating from very small particles of crystalline silicon. More generally, these Raman spectra are different from Raman spectra recorded on amorphous silicon or electrochemically produced porous silicon, and are close to the Raman spectra of the thin films prepared by low energy cluster beam deposition. We also observe (Fig. 5), as for this last material, a very strong photoluminescence which is typical of porous silicon.

First observations by electron microscopy (S.E.M.) confirm the porous structure (Fig. 6) of this material which looks like a jumble of very thin threads. This material seems close to the one obtained by Kamalakaran et al. [19] who use thermal evaporation of silicon in helium gas. More accurate observations by HRTEM, performed after the symposium by Brun [20] show that these threads are made of an association of nanoparticles of silicon, some of them exhibiting crystalline structures.

Small-angle scattering of X-ray also reveals the porous structure of our samples. However the decay of the intensity with increasing scattering angle cannot be clearly interpreted with one of the classical model alone.

More refined studies are now in progress to increase our knowledge of the physical properties and structure of this material. They also involve the study of possible change of its properties by convenient choice of physical conditions during the sublimation process.

\section{Conclusion}

These present experiments point out many advantages of the sublimation-condensation method using a solar furnace. In the case of the synthesis of fullerenes, efficiencies reaching $20 \%$, are greater than those obtained with electrical arc. These results are in agreement with the Smalley's model and differences with laser method can be explained by temperature effects in the vaporization zone which is lower in our experiments. With some modifications of the small 


\section{ENERGY (eV)}
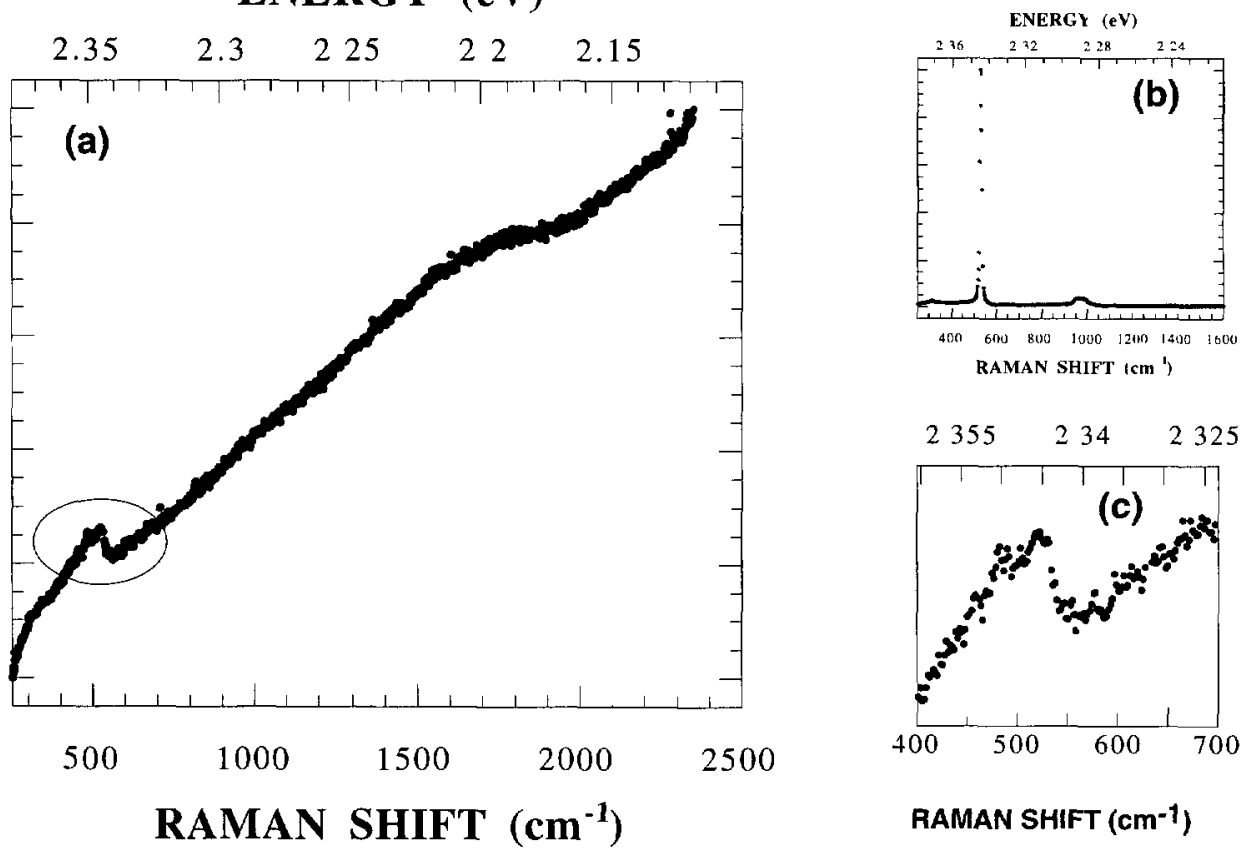

Fig. 4 - Raman spectra: a) porous silicon obtaned by vaponzation with solar furnace; b) crystallıne silicon, c) some details of Raman spectra of our porous silicon.

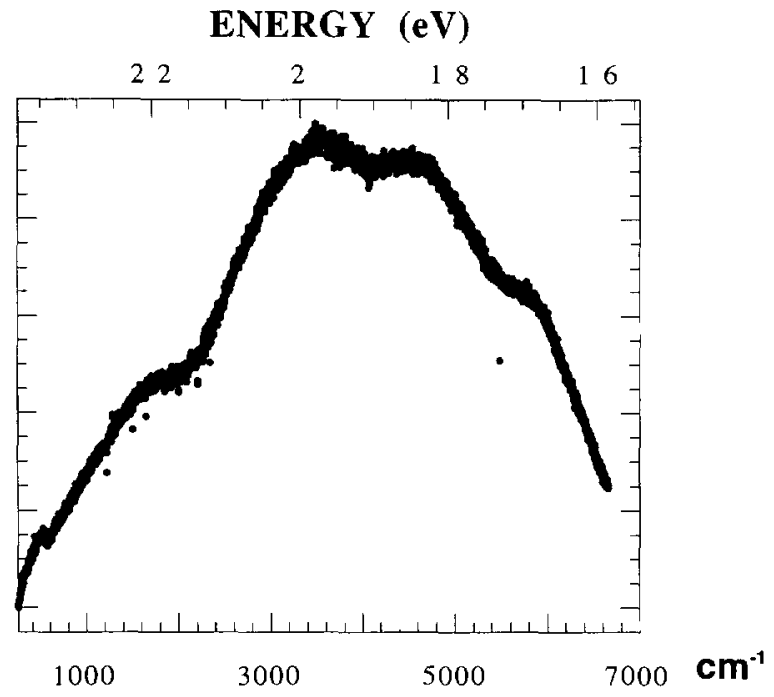

Fig 5 - Photoluminescence spectrum of porous silicon obtained by vaporization with solar furnace Exited with radiation of wave length $514.5 \mathrm{~nm}$, the photoluminescent band is centered around $652 \mathrm{~nm}$ 
a)

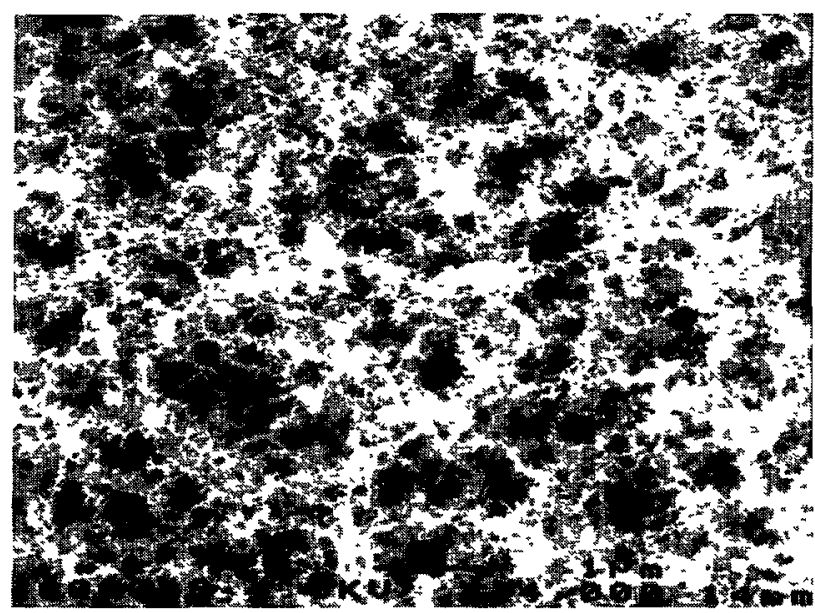

b)

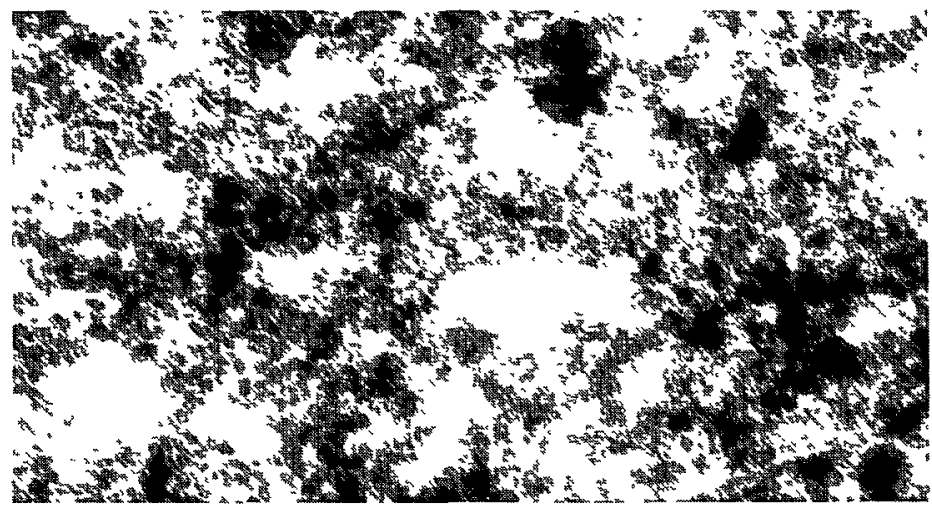

Fig. 6 - S.E M electron micrography (a) depicting porous structure of the obtained Si material (mag $14 \mathrm{k}$ ) and (b) TEM micrography (mag. $40 \mathrm{k}$ ).

scale experimental set-up, specially varying the flow rate of inert gas at constant pressure, we think we can get more information about pressure effects, annealing conditions and probably increased efficiencies. But, to raise the temperature in the vaporization zone up to $3300 \mathrm{~K}$ and use a part of the focussed power to bleach out in a convenient way the carbon vapour, experiments with the great $1 \mathrm{MW}$ solar furnace are required.

On other hand we plan to use the small scale set-up for the vaporization of other materials, such as silicon, looking for the productıon of nano-materials which could have interesting properties.

\section{References}

[1] Chibante L.F.P., Thess A., Alford J , Diener M.D. and Smalley, J Phys Chem 97 (1993) 8696.

[2] Howard J.B., McKinnon J.Th., Makarovsky Y., Lafleur A.L. and Johnson M.E., Nature 352 (1991) 139. 
[3] Wright J.D., "C, Soot and Sun", French-American work-shop, Odeillo (France, October 1995).

[4] Kratschmer W., Lamb L.D., Fostiropoulos K and Huffman D.R., Nature 347 (1990) 354.

[5] The fullerenes, H. Kroto, J. Fisher and D. Cox, Eds. (Pergamon Press, 1993)

[6] Field C.L., Parker D.H., Pitts J.R., Hale M.J., Bingham C., Lewandowsky A. and King D.E., J. Phys Chem. 97 (1993) 8701.

[7] Laplaze D., Bernier P., Barbedette L., Lambert J.M., Flamant G., Lebrun M., Brunelle A. and Della-Negra S., C.R. Acad. Sci. Parıs 318 serie II (1994) 733.

[8] Laplaze D., Bernier P., Flamant G, Lebrun M., Brunelle A. and Della-Negra S., Synt. Met. 77 (1995) 65.

[9] Curl R.F. and Smalley R.E., Scr. Am. 10 (1991) 265.

[10] Haufler R.E., Chai Y., Chibante L.P.F., Conceicao J., Jin C., Wang L.S., Maruyama S. and Smalley R.E., Mater. Res. Soc. Symp. Proc. 206 (1991) 627.

[11] Catalan J., Saiz J.L., Laynez J.L, Jagerovic N. and Elguero J., Angew. Chem. Int. Ed Engl. 34 (1995) 105.

[12] Achiba Y., "C, Soot and Sun". French-American Work-shop, Odeillo (France. October, 1995).

[13] Ebesen T.W., Tabuchi J. and Tanigaki K., Chem. Phys. Lett 191 (1992) 336.

[14] Chaurand P., Thèse, Université Paris-Sud (France, 1994).

[15] Lambert J.M., Thèse, Université Montpellier II (France, 1995).

[16] Schwarz H., Angew. Chem. Int. Ed. Engl. 32 (1993) 1412.

[17] Maser W.K., Lambert J M., Ajayan P.M.. Stephan O. and Bernier P., Syn. Met. 77 1-3 (1995) 243.

[18] Melinon P, "C, Soot and Sun", French-American work-shop, Odeillo (France, October, 1995).

[19] Kamalakaran R., Singh A.K. and Srivastava O.N., J. Phys. Condens. Matter 7 (1995) 529.

[20] Brun N. and Colliex C., private communication 